\title{
Proximal Sural Artery Flap for Knee Defects
}

Ganji Raveendra Reddy, M.S, M.Ch ${ }^{1}$, A R Ch Mohan, M.S, M.Ch², B Jyothsna, M.S, M.Ch ${ }^{3 *}$, D Balaji Sasidhar Reddy, M.S, M.Ch${ }^{4}$, Poornachandra Rao, M.S, M.Ch ${ }^{5}$

${ }^{1}$ Associate Professor, Department of Plastic Surgery, GGH, Vijayawada, India

${ }^{2}$ Professor, Department of Plastic Surgery, GGH, Vijayawada, India

${ }^{3}$ Assistant Professor, Department of Plastic Surgery, GGH, Vijayawada, India

${ }^{4}$ Orthopedic Surgeon, Sri Ramadevi Super Speciality Hospital, Tirupati, India

${ }^{5}$ Orthopedic Surgeon, Remedy Hospital, Tirupati, India

DOI: $\underline{10.36347 / \mathrm{sasjs} .2020 . \mathrm{v} 06 \mathrm{i} 02.007}$

| Received: 30.01 .2020 | Accepted: 06.02.2020 | Published: 18.02.2020

*Corresponding author: Dr. Jyostna P

\section{Abstract}

Original Research Article

Proximal sural artery flap is one of the dependable options standing first on the list to reconstruct the knee defects. In our series of 9 cases which were done in between 2017-2020, for various knee defects following road traffic accidents, tumor exicision, metal exposure, proximal sural artery flap was used to resurface knee. Hand held Doppler was not used to locate perforators in any case. All the cases were performed without tourniquet. Results were quite satisfactory with near normal skin, thickness, color, and sensation. Execution of the procedure is relatively easy even in fatty individuals in comparison to the thigh flaps. Post operative complications were negligible, with no total flap loss in any case, with minimal donor site morbidity.

Keywords: proximal sural artery flap, knee defects, knee debridement.

Copyright @ 2020: This is an open-access article distributed under the terms of the Creative Commons Attribution license which permits unrestricted use, distribution, and reproduction in any medium for non-commercial use (NonCommercial, or CC-BY-NC) provided the original author and source are credited.

\section{INTRODUCTION}

Defects in and around the knee are certainly challenging to a reconstructive surgeon, because of its location over mobile joint, which often demands a stable, pliable tissue with sensation. Meeting these demands, proximal sural artery flap appears to be one of the best choices [1]. It has thin skin when compared with thigh skin flaps, color is near normal to knee skin, sensation is quite satisfactory due to sural nerve, dimensions are quite enough to cover entire anterior surface of knee, apart from- it is having reliable blood supply based on the sural arteries. Even donor site morbidity is also minimal in comparison to the other alternative choices [2].

\section{MATERIAL AND METHODS}

All the 9 cases were done between 2017 2020 in Department of Plastic Surgery, GGH, Vijayawada and Sri Ramadevi Super Speciality Hospital, Remedy Hospital, Tirupati, India. The causes for the knee defects were following road traffic accidents, tumor exicision and exposure of plate screws. The age group range from 20 years to 50 years. Males were 8 and females were 1 in this group. Five cases were presented with skin loss on the accidental site itself, and rest of the four were following delayed skin necrosis after trauma or plate and screw exposure, for which debridement was done before providing flap cover on table. All the defects were in and around the patella on anterior surface. They were all non smokers and non alcoholics. One man was having Diabetes, which is under control. The average size of the defect was $6 \times 9 \mathrm{Cm}^{2}$.

\section{Surgical Technique}

All the cases were done under spinal anesthesia. Patients were kept in prone or lateral position. No tourniquet was used in any case. A reference line was marked from the center of posterior knee crease line to lateral malleolus. Pivot point was fixed $2 \mathrm{~cm}$ distal to this central mark on the reference line. Based on this pivot point, a defect based island flap (in some cases with skin extension as 'sperm shaped') marked on the junction of the middle and distal third of the leg, keeping the reference line in the center, which is indicative of Neuro vascular pedicle by doing 'planning in reverse'. Identification of perforators with hand held Doppler was not done in any case assuming that they were there as described. Then distal incision was made first to identify the sural nerve and short saphenous vein, which was clamped with hemostats ligated and divided. Then the dissection continued all along the markings, raising dermal flaps 
over the bridge segment on either side keeping subcutaneous pedicle with its neuro vascularity. The average width of the pedicle was maintained at $4 \mathrm{~cm}$, on either side of the neuro vascular structures. Flap harvestation continued till the pivot point securing heamostasis, simultaneously assessing the reach of the flap to the defect. Then sub cutaneous tunnel created from the pivot point to the defect to bring the flap to the defect. In cases where, flap was raised with skin extension over pedicle, the bridge segment was incised undermined on either side to accommodate the pedicle skin to avoid tension and compression. Flap inset was given adequately without any tension over suture line after keeping drain. Donor site reduced and bridge segment closed primarily. Left over raw area was cover with split thickness skin graft taken from the thigh and tie over dressing applied. Posterior slab was provided with good padding over pedicle and pivot point to avoid compression. Post operatively limb was elevated by keeping pillow over leg avoiding pressure over posterior aspect of knee for 10 days on an average. Suture removal was done after 2 weeks, mobilization started after 3 weeks depending on other associated injuries.

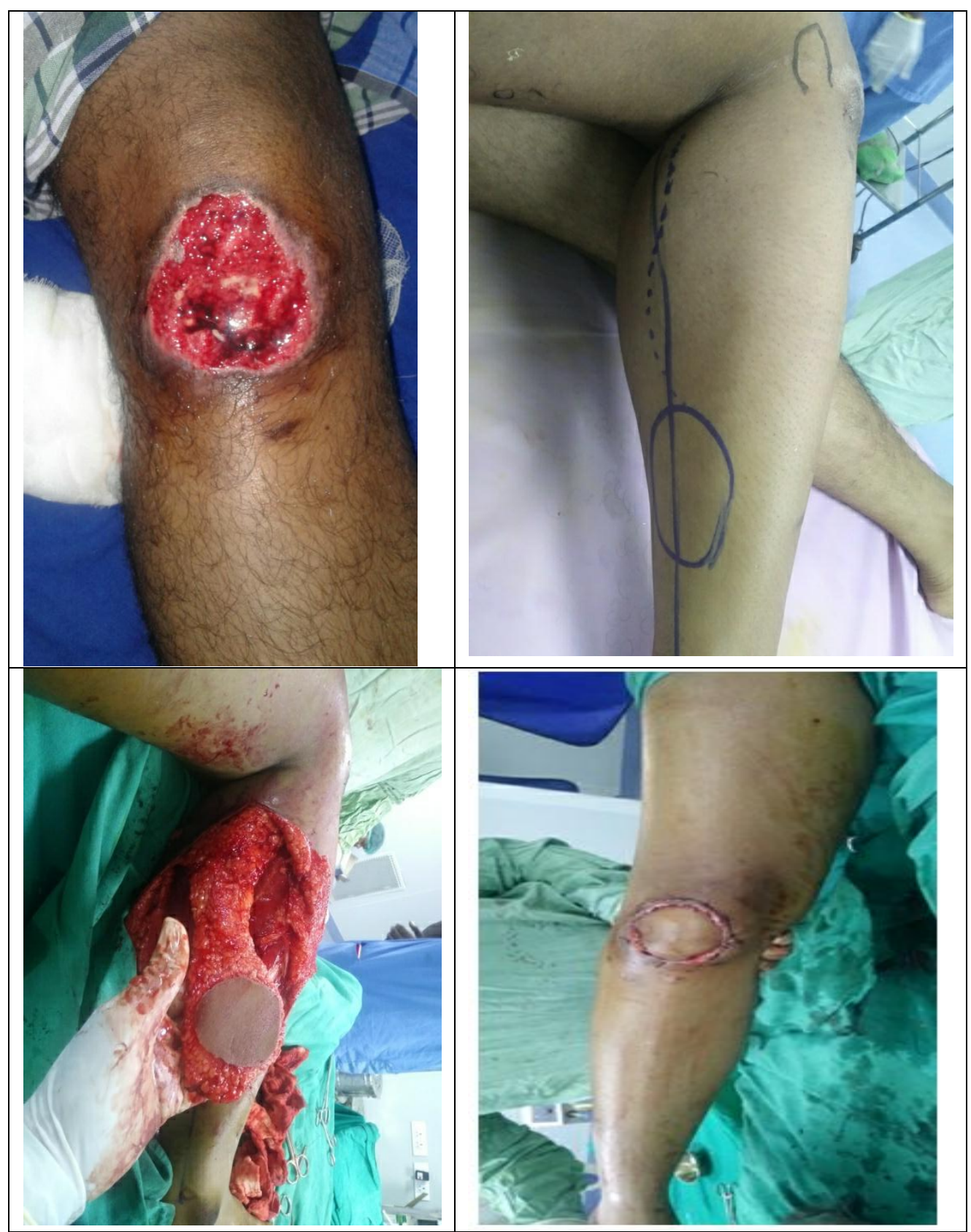

Fig-1: Schematic picture showing pre op defect, planning, flap harvestation, results after two weeks 


\section{RESULTS}

All the flaps were survived. No total loss of flap noted in any case. However, the common complication observed was epidermal necrosis either at the distal end or at the margins of the flap. This was managed conservatively without any debridement to heal by secondary intention as it is partial dermal loss.
Similarly in one case with distal necrosis was managed conservatively with regular dressings - no skin grafting was done. Donor site graft take was also satisfactory and healed primarily. The color thickness pliability was well matched on par with the surrounding skin. Over all patient satisfaction was good.

Table-1: Schematic representation of out come

\begin{tabular}{|l|l|l|l|l|l|l|}
\hline $\begin{array}{l}\text { S. } \\
\text { No }\end{array}$ & $\begin{array}{l}\text { Age } \\
(\mathbf{y e a r s})\end{array}$ & Presentation of Defect & $\begin{array}{l}\text { Defect } \\
\text { Dimensions } \\
(\mathbf{C m})\end{array}$ & Risk factor & $\begin{array}{l}\text { Flap } \\
\text { dimension } \\
(\mathbf{C m})\end{array}$ & Complications \\
\hline 1 & 19 & With loss of tissue & $4 \mathrm{X} 4$ & & $5 \mathrm{X} 5$ & Superficialepidermal necrosis \\
\hline 2 & 50 & Surgical debridement & $15 \mathrm{X} 12$ & & $15 \mathrm{X} 12$ & Uneventful \\
\hline 3 & 26 & With tissue loss & $5 \mathrm{X} 6$ & & $6 \mathrm{X} 7$ & Uneventful \\
\hline 4 & 35 & Following debridement & $8 \mathrm{X} 7$ & & $9 \mathrm{X} 8$ & Uneventful \\
\hline 5 & 53 & Tumor exicixion & $8 \mathrm{X} 7$ & $\begin{array}{l}\text { Diabetes } \\
\text { mellitus }\end{array}$ & $9 \mathrm{X} 8$ & Distal necrosis \\
\hline 6 & 25 & With tissue loss & $7 \mathrm{X} 8$ & & $8 \mathrm{X} 9$ & Uneventful \\
\hline 7 & 32 & With tissue loss & $4 \mathrm{X} 12$ & & $5 \mathrm{X} 12$ & Uneventful \\
\hline 8 & 41 & $\begin{array}{l}\text { Wound gap following } \\
\text { plate and screws }\end{array}$ & $4 \mathrm{X} 10$ & & $5 \mathrm{X} 12$ & Superficial eidermal necrosis \\
\hline 9 & 22 & With tissue loss & $5 \mathrm{X} 6$ & & $6 \mathrm{X} 8$ & Uneventful \\
\hline
\end{tabular}

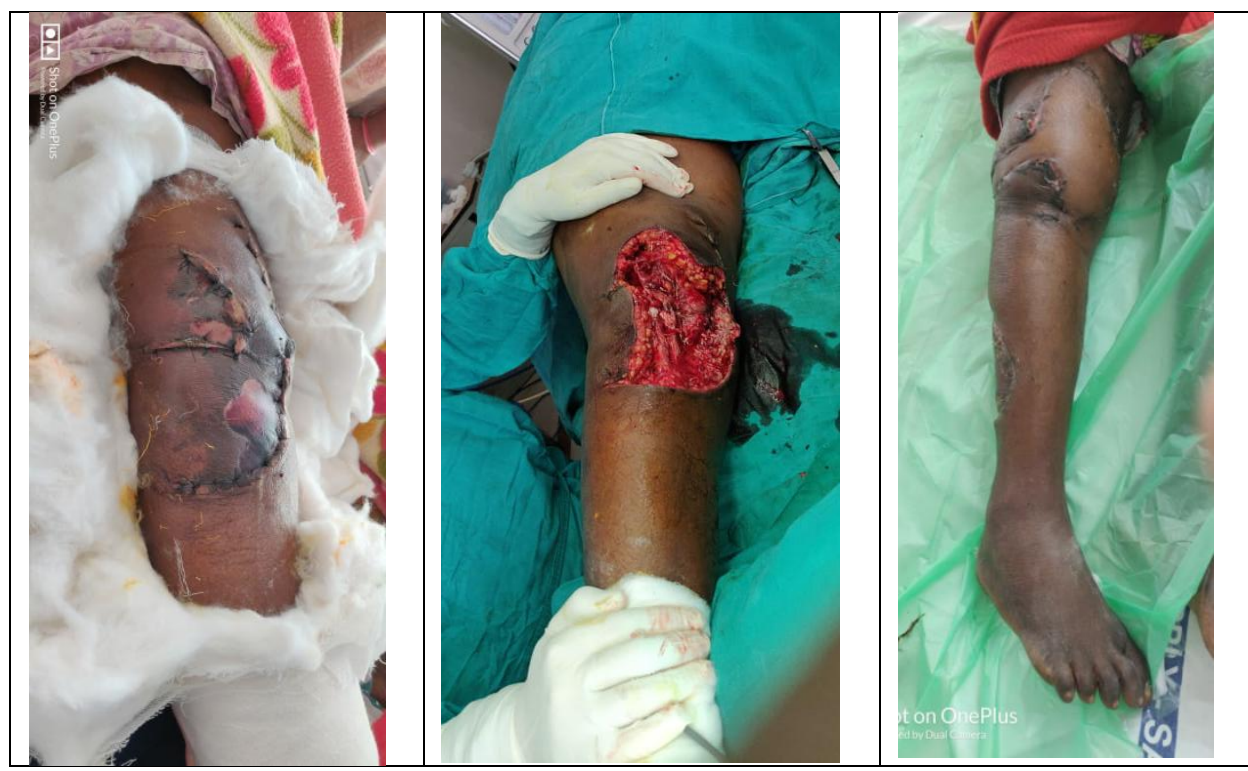

Fig-2: Schematic picture showing delayed necrosis of skin following trauma, defect after wound debridement, resurfaced with proximal sural artery flap-after suture removal

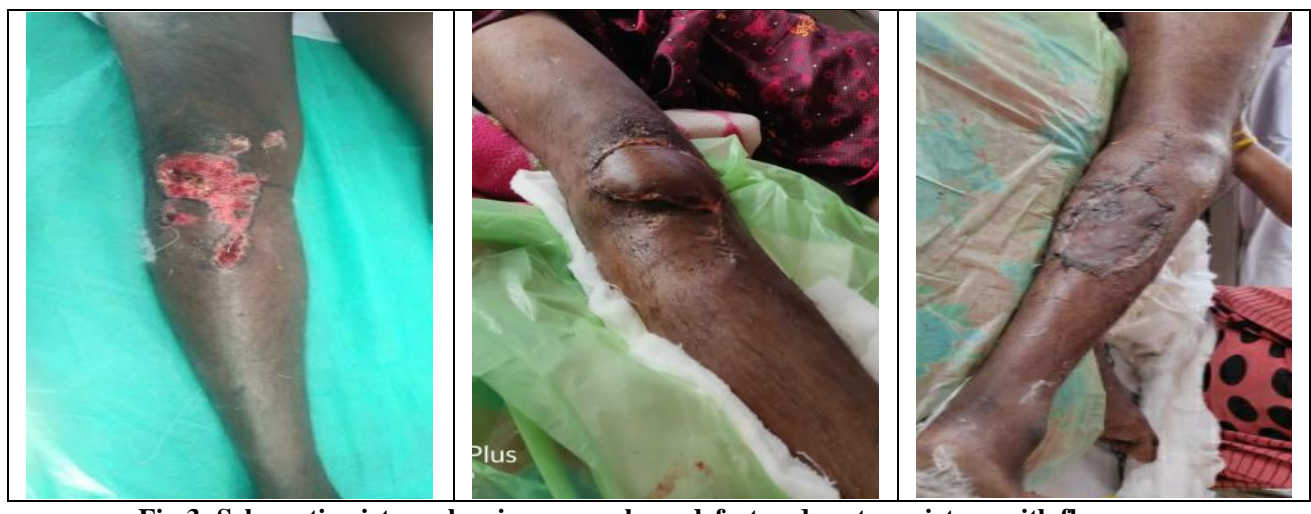

Fig-3: Schematic picture showing pre op knee defect and post op picture with flap cover 


\section{DISSCUSSION}

Before selecting proximal sural artery flap as an option for knee defects, we used to do medial and lateral gastrocnemius muscle and musculo-cutaneous flaps as first option. However, we have noticed that, muscle based flaps are often too bulky and with limited reach up to lower half of the knee. Later we shifted our focus on distal based medial and lateral genicular artery flaps from thigh with retrograde blood supply as an other alternative. In planning these flaps location of perforator is sublime and plays a key role. The flaps are too big and bulky hence rotation is often technically difficult unless perforator is totally skeletonised, taking the imminent risk of venous congestion. And in females technical difficulty is further enhanced due to cumulative fat on the thigh [3].

To overcome these odds, we started applying proximal sural artery flap for the knee defects since 2017 with quite satisfactory results with good patient compliance. Proximal sural artery flap is based on the sural artery (medial, median and lateral sural arteries), which are often direct branches of popliteal artery and in few cases from genicular arteries (medial or lateral). These arteries supply the skin of calf region especially upper two third of leg. The sural arteries are so consistent that, no need to use Doppler to locate the perforators. These arteries accompany the sural nerve throughout its course and joins with the perforators of peroneal artery distally, which is the basis for 'reverse sural artery flap'. It is a fascio cutaneous flap. The exact flap dimensions are not clearly defined. However in our series, we have found that, side to side- from lateral midline to medial midline, proximo distally- from knee crease line to junction of middle and distal third of leg can be harvested safely without compromising circulation to the flap. Flap planning and size is depending on the defect dimensions. Flap can be harvested as an island flap with sub cutaneous pedicle, or as a pedicle flap. Apart from these two, there is another variation, which is an island with skin extension over pedicle like a tail - 'sperm shaped', to lay over at the bridge segment between the pivot point and the defect - to avoid tension over pedicle. In cases of 'island' type, flaps are passed subcutaneously through a tunnel by creating adequate pocket [4]. In both variations flaps behaved well without compromising circulation. Sural artery is accompanied by two venae commitantes with antegrade blood flow and also having short saphenous vein and sural nerve, thus venous congestion is rarely observed in these flaps. The marginal epidermal necrosis of the flap was probably due to shearing force between the skin and fascia, which has been overcome by meticulous dissection and simultaneous fixation of two in our later cases. Donor site complications like minimal graft loss are not uncommon either due to pressure from plaster slab or depending position of the graft. Sensation of the flap is also quite satisfactory in compare to flaps of other options due to intact sural nerve [5].

Overall the merits of the proximal sural artery flap with its ease of dissection (even without tourniquet), consistent perforators (no need of Doppler), ante grade blood supply, adequate venous drainage, thin skin- made superior among surrounding peer flaps and with satisfactory outcome [6].

\section{REFERENCES}

1. Deng C, Wei Z, Wang B, Jin W, Zhang W, Tang X, Wu B, Sun G, Wang D. The proximally based lateral superficial sural artery flap: a convenient and optimal technique for the reconstruction of soft-tissue defects around the knee. Int J Clin Exp Med. 2016 Jan 1;9(8):15167-76.

2. Masquelet A C, Romana M C, Wolf G. Skin island flaps supplied by the vascular axis of the sensitive superficial nerves: anatomic study and clinical experience in the leg. Plast Reconstr Surg, 1992; 89(6)1115-1121.

3. Suri MP, Friji MT, Ahmad QG, Yadav PS. Utility of proximally based sural artery flap for lower thigh and knee defects. Ann Plast Surg, 2010;64:462-465.

4. Pan H, Zheng Q, Yang S. Utility of proximally based sural fasciocutaneous flap for knee and proximal lower leg defects. Wounds, 2014;26:132138.

5. Cheon SJ, Kim IB, Park WR, Kim HT. The proximally-based sural artery flap for coverage of soft tissue defects around the knee and on the proximal third and middle third of the lower leg: 10 patients followed for 1-2.5 years. Acta Orthop, 2008;79:370-375.

6. Meyer C, Hartmann B, Horas U, Kilian O, Heiss C, Schnet-Tler R. Reconstruction of the lower leg with the sural artery flap. Langenbecks Arch Surg, $2002 ; 387(7-8) 320-325$. 